\title{
Sustainability Performance Measurement
}

\section{A Preliminary Classification Framework of Models and Indicators}

\author{
Dries Couckuyt $^{1(\mathbb{*})}$ (D), Amy Van Looy $^{1}$ (D), and Manu De Backer ${ }^{1,2}$ (D) \\ ${ }^{1}$ Department of Business Informatics and Operations Management, Faculty of Economics \\ and Business Administration, Ghent University, Tweekerkenstraat 2, 9000 Ghent, Belgium \\ \{Dries. Couckuyt, Amy. VanLooy, Manu. DeBacker\} @ugent. be \\ 2 Department of Management Information Systems, Faculty of Economics and Business \\ Administration, University of Antwerp, Prinsstraat 13, 2000 Antwerp, Belgium
}

\begin{abstract}
In this position paper we focus on the diversity of sustainability measurements. Based on existing research on performance measurement, we propose a preliminary classification framework summarizing sustainability models and indicators. By describing illustrative examples, we claim that several models and indicators can be distinguished with their own peculiarities. Having such a framework is interesting for both academia and business to structure the range of models and indicators and to ultimately select the appropriate sustainability measurement approach. The proposed framework should be validated by further research.
\end{abstract}

Keywords: Sustainability $\cdot$ Green BPM $\cdot$ Performance measurement

\section{Introduction}

Sustainability gained momentum for practice and research in recent years. Organizations introduce sustainable technologies and focus on optimizing their operations in a sustainable way in order to meet customer demands and jurisdictive requirements [13]. For this purpose, business process management (BPM), which refers to a body of methods, techniques and tools to discover, analyze, redesign, execute and monitor business processes [1], is a key starting point. The objectives of conventional BPM methods and techniques, however, typically refer to cost, quality, time, and flexibility improvements - the so-called 'devil's quadrangle' [16]. Since sustainability also gained importance in the field of BPM, [18] call for an extended version that also includes sustainability as a fifth process performance dimension.

This position paper aims at providing a way to classify performance measurements from the perspective of sustainability. We will propose a preliminary classification framework to better understand the variations in sustainability performance measurement. This framework can provide a foundation for future sustainability performance measurement research striving to advance a sustainable perspective in BPM research and practice. 


\section{Sustainability in BPM}

The Triple Bottom Line defined three interdependent dimensions of sustainability (i.e. economic, social and environmental) on which organizations should focus in order to succeed in the long run [2]. It could be argued that the economic dimension of sustainability is already included in conventional BPM as it optimizes processes along time, cost, quality, and flexibility. Concerning the other two dimensions, the existing approaches in the area of sustainability and BPM are primarily focusing on the environmental scope, and often overlooking the social aspect [11, 19]. Previous literature reviews mention several contributions to the field of Green BPM which concerns the ecological impact of business processes $[5,15,19]$. We are aware that a full integration of sustainability in the BPM discipline also requires research and practice on the social dimension. However, because sustainability is interpreted in environmental terms by a majority of authors in the BPM discipline, the present article continues with the same comprehension and thus discusses measurements of sustainability in light of ecology.

\section{Sustainability Performance Measurement}

As organizations aim to achieve outstanding results, performance measurement is of crucial importance. By reviewing extant literature, [20] identified two groups of papers on this topic. The first group focused on performance measurement models; the second on performance indicators. For the first group, they distinguished models focusing on the entire organization from models focusing on a single business process. For each type of performance measurement model, indicators should be defined. A performance indicator describes how it is measured and how it can be compared against a target value. For instance, an ecological performance indicator can be measured in $\mathrm{CO}_{2}$ per process instance with a target value of zero, meaning that the aim is to eliminate carbon completely. For this second group, a further distinction was made between indicators found with operationalization (i.e., concretization by means of a formula) and those without operationalization. Based on these findings, we now propose a framework to classify several sustainability performance measurement models and indicators (Table 1). The remainder of this section describes each category with an illustrative example.

Table 1. Preliminary classification framework of sustainability models and indicators.

\begin{tabular}{l|l|l|l}
\hline \multicolumn{2}{l}{ Sustainability } & \multicolumn{2}{|l}{ Performance measurement model } \\
\cline { 3 - 4 } \multicolumn{2}{l|}{$\begin{array}{l}\text { Performance } \\
\text { indicators }\end{array}$} & Organizational & Business process \\
\cline { 2 - 4 } & Non-operationalized & $\begin{array}{l}\text { e.g. GRI, CSDI } \\
\text { ISO } 14001: 2015\end{array}$ & $\begin{array}{l}\text { e.g. gCO } \\
\text { e.g. 'Green } \\
\text { 'sustainability' }\end{array}$ \\
\hline
\end{tabular}

First, organizational performance measurement models typically intend to provide a holistic view of an organization's performance. In case indicators are concretized by means of a formula, the model includes operationalized performance indicators. For 
instance, The Global Reporting Initiative (GRI) [4] offers a voluntary reporting framework that contains goals and operationalized indicators with respect to environmental but also economic and social sustainability, i.e. as stated in the Triple Bottom Line [2]. The dimensions are not correlated so the ecological indicators can act as environmental sustainability guidelines for organizations. This is also the case for the Composite Sustainable Development Index $\left(\mathrm{I}_{\mathrm{CSD}}\right)$ [10] which is composed of the economic subindex $\left(\mathrm{I}_{\mathrm{S}, 1}\right)$, the environmental sub-index $\left(\mathrm{I}_{\mathrm{S}, 2}\right)$ and the social sub-index $\left(\mathrm{I}_{\mathrm{S}, 3}\right)$. These subindices are in turn composed of respectively normalized economic, environmental and social indicators extracted from other frameworks (including GRI). For both GRI and CSDI holds that by means of extensive standardization (i.e. operationalization of indicators), companies are offered a tool which allows them to benchmark with other businesses. However, this standardization also impedes the integration of company-specific sustainability endeavors because a general reporting frame is set. Moreover, other dimensions that could be important for the company or stakeholders are neglected if they are not included in the framework.

Secondly, more flexibility is offered by organizational performance measurement models without operationalized indicators. For instance, the Balanced Score Card (BSC) provides four perspectives (i.e. financial, customer, internal processes, learning and growth) for which objectives and performance indicators ensure alignment between strategies and operations [8]. The BSC is an open system which means that all stakeholder interests can be included if they are vital for the success of a strategy. Therefore, it is possible to develop a variant, the Sustainability BSC (SBSC), that integrates strategically relevant environmental goals [12]. Such goals can be integrated into the four existing performance perspectives, or a new key perspective can be added. These SBSCs and associated strategy maps constitute an open framework that comprises sustainability-oriented indicators [6]. Similarly, ISO 14001:2015 [7] provides a framework for environmental management in organizations. It provides guidelines that can be applied to the environmental aspects of activities, products or services in line with organizational objectives. As for SBSC, also these indicators should be defined and operationalized at the individual company level, which means that they are less appropriate for benchmarking.

Thirdly, in addition to organizational models, performance measurement can focus on a single business process. This approach is generally less holistic and provides concrete measurements. For instance, [3] introduced a framework that models the relationship between resources and activities to inform the business process with its carbon emission impact. Besides emissions, literature on the reduction of energy consumption in business processes also presents operationalized performance indicators [17]. These sort of indicators are operationalized with figures and formulas provided by environmental authorities (e.g. grams of $\mathrm{CO}_{2}$ equivalent per kilowatt hour of generation, $\left[\mathrm{gCO}_{2} \mathrm{eq} / \mathrm{kWh}\right]$ ) [3], or rely on accepted measurement units (e.g. Watt seconds [Ws]) [17].

The fourth category covers performance indicators without operationalization for single business processes. For instance, [14] presentes a list of 'Green KPIs' at the business process level (e.g. Power Usage Effectiveness, Data Center Infrastructure Efficiency, Data Center Energy Productivity) without any operationalization of the 
measurements. Similarly, [18] states that business processes should be optimized in light of 'sustainability'. However, to the best of our knowledge, examples of this category are rare in the literature, indicating that scholars mainly propose concrete performance indicators at the business process level. This category has added value from the descriptive point of view and with the intention for operationalization in later work.

\section{Discussion and Conclusion}

Based on existing research on performance measurement, we propose a framework summarizing: (1) sustainability models at the level of an entire organization or a single business process, and (2) indicators, operationalized or non-operationalized by means of a formula. By describing illustrative examples, we show that several models and indicators can be distinguished with their own peculiarities. For instance, a sustainable organizational performance measurement model with operationalized indicators (e.g. GRI) allows to compare between companies in a specific business sector but does not offer the flexibility to integrate company-specific sustainability endeavors (e.g. SBSC).

Since this is a position paper, no structured approach was used to identify all possible sustainable performance models and indicators. Therefore, we recommend to retrieve all available literature on sustainability performance measurement by means of a systematic literature review [9]. Subsequently, the preliminary classification framework can be validated by mapping the identified performance measurement models and indicators. This exercise should also give answer to the question if the proposed categories are sufficient to guide academics and practitioners. Moreover, it will also clarify if double classifications, e.g. a model for both the organizational and process level, exist.

Instead, we now merely focused on the diversity of sustainability measurements to foster further research in the area. A sustainable transition of organizations and underlying business processes will require multiple measurement methods and techniques. Our proposed framework is interesting for both academia and business to structure the range of models and indicators and to ultimately select the appropriate sustainability measurement approach.

\section{References}

1. Dumas, M., La Rosa, M., Mendling, J., Reijners, H.A.: Fundamentals of Business Process Management. Springer, Heidelberg (2013). https://doi.org/10.1007/978-3-642-33143-5

2. Elkington, J.: Cannibals with Forks: the Triple Bottom Line of Sustainable Development, 1st edn. Capstone Publishing, Oxford (1997)

3. Ghose, A., Hoesch-Klohe, K., Hinsche, L., Le, L.-S.: Green business process management: a research agenda. Australas. J. Inf. Syst. 16(2), 103-117 (2009)

4. Global Reporting Initiative. https://www.globalreporting.org/standards/gri-standardsdownload-center. Accessed 30 May 2017

5. Gohar, S.R., Indulska, M.: Business Process Management: Saving the Planet? In: Australasian Conference on Information Systems, Adelaide, pp. 1-14 (2015)

6. Hansen, E.G., Schaltegger, S.: The sustainability balanced scorecard: a systematic review of architectures. J. Bus. Ethics 133(2), 193-221 (2016) 
7. International Organization for Standardization (ISO): ISO 14001:2015 Environmental Management Systems - Requirements with Guidance for Use. https://www.iso.org/obp/ui/ \#iso:std:iso:14001:ed-3:v1:en

8. Kaplan, R.S., Norton, D.P.: The Balanced Scorecard: Translating Strategy into Action, 1st edn. Harvard Business School Press, Boston (1996)

9. Kitchenham, B.: Procedures for performing systematic reviews. Keele University, Keele, Technical report, pp. 1-28 (2004)

10. Krajnc, D., Glavič, P.: A model for integrated assessment of sustainable development. Res. Conserv. Recycl. 43, 189-208 (2005)

11. Magdaleno, A.M., Duboc, L., Betz, S.: How to Incorporate Sustainability into Business Process Management Lifecycle? In: Dumas, M., Fantinato, M. (eds.) BPM 2016. LNBIP, vol. 281, pp. 440-443. Springer, Cham (2017). https://doi.org/10.1007/978-3-319-58457-7_32

12. Möller, A., Schaltegger, S.: The sustainability balanced scorecard as a framework for ecoefficiency analysis. J. Ind. Ecol. 9(4), 73-83 (2005)

13. Nowak, A., Leymann, F., Schumm, D.: The differences and commonalities between green and conventional business process management. In: International Conference on Dependable, Autonomic and Secure Computing Proceedings, pp. 569-576. IEEE, Sydney (2011)

14. Opitz, N., Erek, K., Langkau, T., Kolbe, L., Zarnekow, R.: Kick-starting green business process management - suitable modeling languages and key processes for green performance measurement. In: Americas Conference on Information Systems Proceedings, Seattle, pp. 1$10(2012)$

15. Opitz, N., Krüp, H., Kolbe, L.M.: Green business process management - a definition and research framework. In: Hawaii International Conference on System Sciences Proceedings, pp. 3808-3817. IEEE, Waikoloa (2014)

16. Reijers, H.A., Mansar, S.L.: Best practices in business process redesign: an overview and qualitative evaluation of successful redesign heuristics. Omega 33(4), 283-306 (2005)

17. Reiter, M., Fettke, P., Loos, P.: Towards green business process management: concept and implementation of an artifact to reduce the energy consumption of business processes. In: Hawaii International Conference on System Sciences Proceedings, pp. 885-894. IEEE, Waikoloa (2014)

18. Seidel, S., vom Brocke, J., Recker, J.: Call for action: investigating the role of business process management in green IS. In: All Sprouts Content, pp. 1-6. AISeL (2011)

19. Stolze, C., Semmler, G., Thomas, O.: Sustainability in business process management research - a literature review. In: Americas Conference on Information Systems Proceedings, pp. 110. AISeL, Seattle (2012)

20. Van Looy, A., Shafagatova, A.: Business process performance measurement: a structured literature review of indicators, measures and metrics. SpringerPlus 5(1), 1-24 (2016) 